grant to mankind, shonld never be entirely lost sight of, and thus we often perceive when a subject appears to lie most dormant, which perhaps at a previous season had awakened the sensibility of its advocates, that it is again stirred up to active life by some unforeseen and unexpected occurrence. In this instance the idea of the existence of indivisible atoms seems, from various circumstances, to have been handed down from the earliest ages, and the Bramins, the Egyptian priesthood, the sages of Greece, the schoolmen of the middle ages, and the metaphysicians of Germany, were nothing more than the instruments, like Newton and Higgins, in the hands of Providence, to draw the casual atiention of the learned to a subject, the fruits of which it was her wish to confer upon them, when the wider diffusion of knowledge should render them capable of receiving it. Until the arrival of this eventful period, it was necessary that the understandings of the learned should be occasionally directed to it, in order to prepare the minds of the rest of mankind for its genuine invention.

After Higgins had stirred up the embers of this apparently dying flame, it was again allowed to sleep for a few years, and then the season for making it generally known having arrived, Dalton appeared on the stage of philosophical inquiry.

(To be continued.)

CASE OF

\section{DROPSY OF THE PERITONEUM}

OF ELEVEN YEARS DURATION, CURED BY INUNCTION WITH

\section{HYDRIODATE OF POTASH AND MERCURY.}

By W. Bevan, A. M., MI. R. C.S.I., and one of the attending Surgeons to St. Peter's Parochial Dispensary, Dublin.

Margaret Powtan, atat. 41, servant, of a robust and healthy constitution, having run through the ordinary course of pregnancy, was, in the month of February 1823 , admitted into the Dublin Lying-in Hospital, when, the labour being a protracted one, she was delivered, per force, of a dead child. Contrary to the consent of the attending physician, she went out prematurely, and returned immediately to her situation.

About seven or eight months after, being enceinte, she perceived that she was larger than usual under the circumstances, and that there existed an evident division between the upper and lower halves of the abdomen. Having gone her full time, she was delivered of a still-born child, and immediately after delivery observed that she was scarcely if at all reduced in size, which was considerable. Soonafter this she again became pregnant, and in due time was safely delivered of a liviny child. Nothing, however, during this long period had been done for the extra swelling of the abdomen, which had become much larger, and continued to increase. A third time she became pregnant, and after the usual period was a second time delivered of a. still-born child. This occurred four years after her first accouchment. As yet, also, nothing was done for the tumour, which continued to enlarge.

Unwilling to consent to the use of any remedy, and not imagining that she was dropsical, two years subsequent to this time, having ceased child-bearing, and having become very helpless, and being incapable of motion, she applied to a physician, who gave it as his opinion, that she really was dropsical, and that she must immediately be tapped. To this she consented, and the operation was accordingly performed in ihe presence of three attend. ants, when thirty-nine quarts of a limpid serum were drawn off. From that period to the present time she has been tapped once in each year, except the last, when it was performed thrice, in consequence, as is usual, of the more rapid and frequent effusion of fluia. On an average, eighteen quarts of water were evacuated each time. In two instances none could be obtained.

In the beginning of January of the present year, the tumour heving again increased much and rapidly, I was applied to, by her attending physician, to perform the operation, when we drew off fourteon quarts of a thickish serum. Much difficulty and resistance were experienced on introducing the trocar, the integuments being very dense, and the peritonenm feeling as hard as pasteboard. I did not succeed in drawing off all the water at this time; a third part still remained. A fiannel roller being applied, and a portion of the Decoct. Seminis Lini. being directed to be taken daily (the urinary secretion having been some time suspended), we left her.

Subsequently, on inquiring into the history of her case, I found that during the long period of ten years, her health had not materially suffered, that the uterus, the catamenia being always regular, the kidneys, and especially the liver, had performed their functions well. I, therefore, concluded that the disease had its seat and origin in the peritoneum, in consequence of latent inflammation, which 
conclusion its thickened and diseased state consequences may ensue. I would further warranted me in drawing. With this remark, that when it is perceived in a case view of the case, I directed her to use the following ointment :-

\section{Bo Ung. Hydriod. Potassa,}

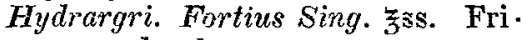
catus drachma mane nocteque abdlom.

\section{of dropsy that iodine has manifested its} effects, the radical cure may be very much hastened by lrawing off any remaining fluid, - probably the last time the operation will be necessary. The evil consequences arising from a lengthened use of the remedy may thus be obviated. Lastly, I would add, that I think iodine is materially

Three weeks after she had discontinued the use of the ointment, and finding that the swelling had rather diminished than increased, I determined on drawing off the remainder of the fluid, which I accordingly did, when thirteen quarts of a thickish brick-red-coloured serum flowed out. I was much surprised to find the abdominal parietes this time quite relaxed and pliable. This enabled me to take away the last drop. Having applied a tight bandage, and directed her to remain at rest for some days, I desired that she should take exercise; since which she has resumed her natural dinensions, has returned to service, and continues to improve in health, and no disposition seems to exist at present to renew the disease, a period of five months having now elapsed.

On a review of this case I consider it to be interesting on two accounts. First, that during the unusual length of time in which this individual was dropsical, there was a total absence of symptoms of injury in the other organs, particularly the stomach; the menstrual flux also being sin. gularly regular throughout. Secondly, the remarkably quick and rapid effect produced by the ointment. This I conceive was due to the hydriodate, its now wellknown power on the constitution of thinning and emaciating, being strikingly shown in this instance. But $I$ think that it possesses, in addition, a much more valuable property, that of altering the diseased action of a part, which $I$ consider was manifested in this case by the marked alteration in colour of the fluid. This also occurred in a case of ovarian dropsy treated with iodine by Dr. Elliotson, and also by Dr. Thompson of London, who (though I was ignorant of the fact till $I$ had consulted the journals; have used this substance as a remedy in this form of disease, often with success. Dr. E. in his lectures has given some useful and judicious directions on its use, and has, I think, observed that it is likely to prove a good and valuable remedy. Let me, however, add, that much caution and circumspection should be observed in using it, either internally or externally, as, both from its rapid effects, its action, and its decided tendency to engender an inflammatory state of the system, dangerous mercury.

Dublin, June, 1834.

\section{SEVERE HEMORRHAGE}

FROMI AN

\section{ULCER ON THE PENIS.}

\section{To the Editor of THe LANCET.}

Sir - If the following case is worthy of insertion, you will, perhaps, give it a place. I am, Sir, your very obedient and humible servant,

\section{Southampton, June 13th, 1834.}

Case. - Coombs, about twenty years of age, sent for me to stop a bleeding. which had taken place from the penis. He was a stout healthy young man, and had had hemorrhage several times for two or three days previous to my seeing him, but since this last occurrence he had become so completely exhausted as to be unable to stand. I examined the vessel on my arrival into which the blood had been received; it contained about two pounds or more of arterial fluid, and which only ceased to flow on the approach of fainting. A large clot filled up the lips of the prepuce, which was swollen and inflamed, and nearly closed over the glans by a phymosis.

He stated that he had lost a larger quantity of blood by the previous bleedings, and, judging from his appearance, I should say he certainly had sustained a considerable loss of that element, since he was blanched, and almost unable to move.

After drawing away the coagulum, $I$ in. troduced the blade of a curved pair of scissars, and slit the prepuce as far as the margin of the glans, when, on reflecting its divided edges, alarge chancrous ulceration, comprehending a third of the corona and body of the glans, was exposed. After wash. ing the parts, the nitrate of silver was freely applied, so as to act as an escharotic; a piece of dry lint was placed over the sore, and the penis was covered with rags dipped in cold water. By the next day the slough came away, and no hemorrhage ensued. 